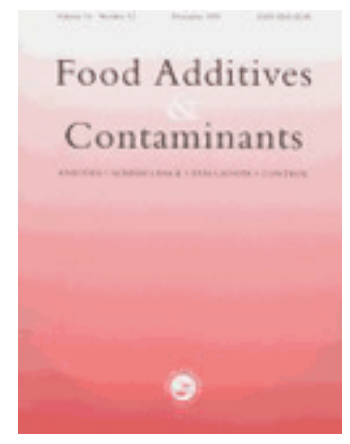

\title{
Analysis of polycyclic aromatic hydrocarbons in vegetable oils combining gel permeation chromatography with solid phase extraction cleanup
}

\begin{tabular}{|r|l|}
\hline Journal: & Food Additives and Contaminants \\
\hline Manuscript ID: & TFAC-2006-221.R1 \\
\hline Manuscript Type: & Original Research Paper \\
\hline Date Submitted by the & 23-Nov-2006 \\
\hline Complete List of Authors: & $\begin{array}{l}\text { Fromberg, Arvid; Danish Institute for Food and Veterinary } \\
\text { Research, Department of Food Chemistry } \\
\text { Højgård, Arne; Regional Veterinary and Food Administration Centre, } \\
\text { Region North } \\
\text { Duedahl-Olesen, Lene; Danish Institute for Food and Veterinary } \\
\text { Research, Department of Food Chemistry }\end{array}$ \\
\hline Mdditives/Contaminants: & PAH, Process contaminants - PAH's \\
\hline Food Types: & Oils and fats, Olive oil \\
\hline
\end{tabular}

\section{SCHOLARONE ${ }^{m}$ Manuscripts}




\title{
Analysis of polycyclic aromatic hydrocarbons in vegetable oils combining gel permeation chromatography with solid phase extraction cleanup
}

\author{
Arvid Fromberg $^{* 1}$, Arne Højgård ${ }^{2}$ and Lene Duedahl-Olesen ${ }^{1}$ \\ ${ }^{1}$ Danish Institute for Food and Veterinary Research, Department of Food Chemistry, \\ Mфrkhфj Bygade 19, DK-2860 Sфborg, Denmark. \\ ${ }^{2}$ Regional Veterinary and Food Administration Centre, Region North, Sфnderskovvej 5, \\ DK-8520 Lystrup, Denmark
}

\begin{abstract}
A semi-automatic method for the determination of polycyclic aromatic hydrocarbons in edible oils using a combined Gel Permeation Chromatography/Solid Phase Extraction (GPC/SPE) clean-up is presented. The method takes advantage of automatic injections using a Gilson ASPEC XL sample handling system equipped with a GPC column (SX3) and pre-packed silica SPE columns for the subsequent clean-up and finally gas chromatography-mass spectrometry (GC-MS) determination. The method was validated for the determination of PAHs in vegetable oils and is able to meet the criteria for the official control of benzo[a]pyrene levels in foods laid down by the Commission of the European Communities. A survey of 69 vegetable oils sampled on the Danish market included olive oil as well as other vegetable oils like rapeseed oil, sunflower oil, grape seed oil and sesame oil. Levels of benzo[a]pyrene in all the oils were low $(<0.2-0.8 \mu \mathrm{g}$ $\mathrm{kg}^{-1}$ ), except for one sample of sunflower oil containing $11 \mu \mathrm{g} \mathrm{kg}^{-1}$ benzo[a]pyrene.

\footnotetext{
"Corresponding author. Tel.: +45 7234 6000; fax.: +45 7234 7448; E-mail address: arf@dfvf.dk.
} 
Keywords: Analysis, PAHs, benzo[a]pyrene, method validation, vegetable oil, sunflower oil, rapeseed oil, grape seed oil, sesame oil, GPC, SPE.

\title{
Introduction
}

Polycyclic aromatic hydrocarbons (PAHs) are a group of hundreds of organic compounds, which contain two or more fused aromatic rings made up of carbon and hydrogen. PAHs are formed by the incomplete combustion of organic material like wood, coal or oil. Studies of various matrices, such as coal combustion effluents, motor vehicle exhaust, used motor lubricating oil and tobacco smoke, have shown that PAHs are found in the outdoor air and the indoor environment. However, for non-smokers, human exposure to PAHs occurs mainly via food consumption (IPCS, 1998; European Commission, 2002). The occurrence of PAHs in foods is due to the formation of PAHs during food processing, such as drying, smoking, and domestic food preparation such as barbecuing, roasting and frying.

\begin{abstract}
Although studies on animals exposed to individual PAHs, most notably benzo[a]pyrene, have shown various toxicological effects, such as haematological effects, reproductive and developmental toxicity and immunotoxicity, the critical effects are genotoxicity and cancer. Only very few single PAHs and a few complex mixtures have been toxicologically risk assessed. Recently, the European Scientific Committee on Food (SCF) has risk assessed 33 PAHs. The Committee concluded that 15 PAHs showed clear evidence of genotoxicity, and 14 of these were carcinogenic to animals (European Commission, 2002). However, SCF recommended to evaluate the usefulness of
\end{abstract}


benzo $[a]$ pyrene as a marker for the carcinogenic PAHs in food and to evaluate the risk assessment of the carcinogenicity of PAHs in food based on the level of benzo[a]pyrene.

In 2001, a processing problem caused a general contamination of European olive pomace oils. The awareness of processing problems and the publication in 2002 of SCF's health risk assessment of PAHs exposure from foods (European Commission, 2002) has given rise to novel interests in the field of PAHs in foods. In April 2005, EC maximum levels for benzo[a]pyrene (European Commission, 2005) were adapted for e.g. oils and fats intended for human consumption or use as an ingredient in foods $(2 \mu \mathrm{g}$ $\mathrm{kg}^{-1}$ wet weight). At the same time, minimum performance criteria for sampling methods and for methods of analysis for the official control of benzo[ $[a]$ pyrene levels in foodstuffs were adapted in a Commission Directive (European Commission, 2005a). Commission recommendations on further investigation into the levels of the $15 \mathrm{EU}$ priority PAHs in certain foods were also given (European Commission, 2005b).

Vegetable oils, naturally free of PAHs, are contaminated by technological processes like smoke drying of oil seeds or indirectly by environmental sources, such as exhaust gases from traffic or other combustion derived atmospheric particles deposited on the crops during growing. However, the PAHs content in vegetable oils can be radically reduced during refining, the final level depending on the refining conditions adopted (Hopia et al., 1986; Larsson et al., 1987; IPCS, 1998; Moret et al., 2000). 
Previously, benzo[a]pyrene concentrations below the European Commission maximum limit of $2 \mu \mathrm{g} \mathrm{kg}^{-1}$ have been reported for virgin olive oils (Hopia et al., 1986; Moret et al., 1997; Menichini et al., 1991; Speer et al., 1990; Lodovici et al., 1995; European Commission, 2004). In comparison, surveillance data reflecting targeted sampling of vegetable oils showed that benzo[a]pyrene concentrations in olive pomace oils exceeded the European maximum limit for $83 \%$ of 268 samples (European Commission, 2004).

Pupin and Toledo (1996) found benzo[a]pyrene concentrations for olive oils $(n=7)$ of Argentine origin up to $164 \mu \mathrm{g} \mathrm{kg}^{-1}$, with no further explanation for the high concentrations. Van der Wielen and co-workers (2006) reported benzo[a]pyrene concentrations up to $85 \mu \mathrm{g} \mathrm{kg}^{-1}$ in olive oils ( $\left.\mathrm{n}=170\right)$, while other vegetable oils $(\mathrm{n}=170)$ for human consumption only showed benzo[a]pyrene concentrations up to $9 \mu \mathrm{g} \mathrm{kg}^{-1}$. Crude rapeseed oils have been reported to contain benzo[a]pyrene concentrations ranging from 1.4 to $64 \mu \mathrm{g} \mathrm{kg}^{-1}$ (Dennis et al., 1991), while grape seed oils have been reported to contain average benzo[a]pyrene concentrations of $4.2 \mu \mathrm{g} \mathrm{kg}^{-1} \quad(\mathrm{n}=92)$ (European Commission, 2004) and from 8.6 to $44 \mu_{\mathrm{g} \mathrm{kg}}^{-1}(\mathrm{n}=20)$ (Moret et al., 2000). Sunflower oils $(n=201)$ collected in seven European member states revealed an average value of $3.2 \mu \mathrm{g} \mathrm{kg}^{-1}$ benzo[a]pyrene (European Commission, 2004) with $29 \%$ of all samples exceeding the EU maximum limit of $2 \mu \mathrm{g} \mathrm{kg}^{-1}$.

Literature including results of PAHs for types of vegetable oils other than olive oils have been rare and if other types of vegetable oils were included, only a few samples were reported e.g. one linseed and one sesame oil (Speer et al., 1990), two refined 
rapeseed oils (Larsson et al., 1987) three refined maize oils (Dennis et al., 1991). Furthermore no results have been presented for samples taken after the introduction of the EU maximum limit.

Previously, the German Society for Fat Science fixed a limit of $25 \mu \mathrm{g} \mathrm{kg}^{-1}$ for the total sum of PAHs and a limit of $5 \mu \mathrm{g} \mathrm{kg}^{-1}$ for the sum of PAHs of five or more aromatic rings (Speer et al., 1990, Swetman et al., 1999). In addition a calculation of the sum of genotoxic PAHs analysed are included in the present study.

Traditionally, determination of PAHs has relied on procedures generally consisting of an extraction step (e.g. liquid-liquid partition or saponification) followed by one or more purification procedures (e.g. column chromatography or solid phase extraction (SPE)). Analytical determination has usually been carried out by HPLC coupled to fluorometric or UV detection, or through high resolution capillary GC coupled to flame ionization detection (FID) or mass spectrometry (MS) (Hopia et al., 1986; Larsson et al., 1987; Dennis et al., 1991; Menichini et al., 1991; Moret et al., 2000; Moret and Conte 2000). Among different purification procedures silica gel columns, used alone or in combination with other materials, have been widely used (Moret and Conte 2000). In 1996 Moret and co-workers evaluated the use of SPE silica cartridges for olive oils, and these cartridges were also employed by Swetman et al. (1999) for coconut oil.

The present study presents a semi-automatic method for the determination of PAHs in edible oils using a combined Gel Permeation Chromatography (GPC) and Solid Phase Extraction (SPE) clean-up. The clean-up techniques are based on those described by 
Speer et al. (1990). The method takes advantage of automatic injections and sample handling using a Gilson apparatus and is validated for the determination of a large number of important PAHs in vegetable oils. The analytical method is able to meet the criteria for the official control of benzo $[a]$ pyrene levels in foods laid down by the Commission of the European Communities. The study also includes new data on olive oils and report values for oils commonly used for food preparation in Denmark, but rarely reported in the literature. These oils include rapeseed oils, sunflower oils, grape seed oils and sesame oil.

\section{Methods and materials}

\section{Chemicals}

All solvents used were HPLC-grade or pro analysi. Bio-Beads S-X3, 200-400 mesh was obtained from Bio-Rad Laboratories and Silica Isolute SPE columns $500 \mathrm{mg} / 3 \mathrm{ml}$ from International Sorbent Technology Limited. The individual PAH compounds were obtained from Dr. Ehrenstofer included: Acenaphtylene, Acenaphthene, Fluorene, Phenanthrene, Anthracene, Fluoranthene, Pyrene, Benzo[a]anthracene, Chrysene, Benzo $[b]$ fluoranthene, Perylene, Benzo[j]fluoranthene, Benzo[k]fluoranthene, Benzo[e]pyrene, Benzo[a]pyrene, Indeno[ $[1,2,3-c, d]$ pyrene, Dibenzo $[a, h]$ anthracene, Benzo $[g, h, i]$ perylene, and all the ${ }^{13} \mathrm{C}_{6}$ and $\mathrm{D}_{12}$ labelled compounds were obtained from Cambridge Isotope Laboratories, Inc., including: ${ }^{13} \mathrm{C}_{6}$ labelled Acenaphthene and Fluorene, and $\mathrm{D}_{12}$ labelled Benzo $[a]$ anthracene, Benzo[e]pyrene, Benzo[ $[a]$ pyrene and Indeno[1,2,3-c,d]pyrene. 


\section{Gel permeation chromatography (GPC)}

About $1.5 \mathrm{~g}$ of edible oil was dissolved in cyclohexane-ethyl acetate 1:1 (v/v), and the internal standard containing ${ }^{13} \mathrm{C}_{6}$ or $\mathrm{D}_{12}$ labelled PAHs was added. Half of the sample solution was then added, via a Gilson ASPEC XL apparatus, onto a glass column (15 $\mathrm{x}$ $500 \mathrm{~mm}$ ) packed with pre-swollen and washed Bio-Beads S-X3 corresponding to $24 \mathrm{~g}$ dry material. The column was eluted using cyclohexane-ethyl acetate $1: 1(\mathrm{v} / \mathrm{v})$ at a flow rate of $1.5 \mathrm{ml} \mathrm{min}$. The first fraction $(0-64 \mathrm{ml})$ eluting from the column containing lipids was diverted to waste, after which the PAHs fraction $(65-115 \mathrm{ml})$ was collected. Subsequently the other half of the sample was cleaned up on the column and the combined PAHs fraction was collected, including in total $100 \mathrm{ml}$ of eluate. The solvent was evaporated on a rotary evaporator and subsequently concentrated to $1 \mathrm{ml}$ by blowing with nitrogen.

\section{Silica column clean-up}

A pre-packed silica SPE column was used to remove residue lipids and other disruptive compounds from the GPC cleaned sample using the Gilson ASPEC XL apparatus. After conditioning of the column with cyclohexane, the concentrated sample was added to the SPE column followed by elution using cyclohexane. The cleaned up sample was transferred into a GC-vial equipped with a pointed bottom and the solvent was evaporated to around $50-100 \mu \mathrm{l}$ and afterwards $100 \mu \mathrm{l}$ of the internal injection standard (Benzo[e]pyrene $\mathrm{D}_{12}$ ) was added to the GC-vial. Finally the sample was concentrated to $100 \mu \mathrm{l}$ and analysed using GC-MS (gas chromatograph equipped with a mass spectrometer). The entire sample preparation procedure for sample preparation of edible oils is outlined in Figure 1. 
[Insert Figure 1 here]

GC-MS analysis

The GC-MS analyses were preformed using a 50m DB-5MS (J\&W) column, $0.25 \mathrm{~mm}$ inner diameter, $0.25 \mu \mathrm{m}$ film thickness. The ionisation mode was electron impact at $70 \mathrm{eV}$. The carrier gas used was helium at $1 \mathrm{ml} \mathrm{min}^{-1} .2 \mu 1$ of the cleaned sample was injected splitless with a splitless time of $1 \mathrm{~min}$. The injector was held at $280^{\circ} \mathrm{C}$ and the transfer-line at $280^{\circ} \mathrm{C}$. The $\mathrm{GC}$ oven was held at $90^{\circ} \mathrm{C}$ for $1 \mathrm{~min}$. then raised to $270^{\circ} \mathrm{C}$ at a rate of $7^{\circ} \mathrm{C} \mathrm{min}^{-1}$; further raised to $280^{\circ} \mathrm{C}$ at a rate of $1^{\circ} \mathrm{C} \min ^{-1}$ and finally to $320^{\circ} \mathrm{C}$ at a rate of $5^{\circ} \mathrm{C} \mathrm{min}^{-1}$; and held at $320^{\circ} \mathrm{C}$ for $10 \mathrm{~min}$. The compounds were identified and quantified by comparing retention times and responses with those of standard mixtures. The criteria for identification were same retention times as the standard within $\pm 2 \%$, correct relative abundance of the two characteristic ions within $\pm 15 \%$. Compounds formula, mol weight, retention times, Limit of detection (LOD) and limit of quantification (LOQ) are listed in Table 1.

[Insert Table 1 here]

\section{Method validation}

The analytical method has been validated according to the Danish guidelines for validation of methods in chemical analytical laboratories (Danak 2003) interpreting the 


\section{Sampling of vegetable oils}

The Regional Veterinary and Food Control Authorities in Denmark sampled vegetable oils from merchants. The samples included 52 samples of olive oil, 8 samples of rapeseed oil, 4 samples of sunflower oil, 4 samples of grape seed oil and one sample of sesame oil. All samples were for human consumption, to be used either in private homes or in restaurants or catering firms.

\section{Results and discussion}

\section{Method development}

A part of the method development included the selection of suitable internal standards. Bolt et al. (1997) observed instability of deuterium labelled PAHs due to the loss of deuterium from the labelled compounds. Carbon-13 labelled compounds are therefore 
preferred. However, benzo[a]pyrene D12 was preferred as the internal standard for benzo[ $[a]$ pyrene, as carbon labelled benzo[ $[a]$ pyrene only contains four carbon-13 atoms per molecule and a test showed a peak at the retention time and $\mathrm{m} / \mathrm{z}$ of benzo[a]pyrene probably due to loss of $\mathrm{H}$ from the molecule or due to benzo[ $[a]$ pyrene as impurity in the labelled standard. Difficulties with the loss of deuterium from benzo[a]pyrene D12 have not been observed. Bolt and co-workers did not report any problems with the loss of deuterium from benzo $[a]$ anthracene, and benzo $[a]$ anthracene D12 was therefore used as the internal standard.

Calibration curves 
External standards of all the compounds in solvent were used for the determination of

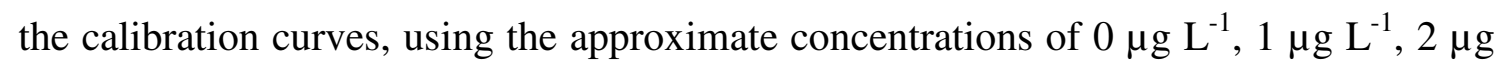
$\mathrm{L}^{-1}, 10 \mu \mathrm{g} \mathrm{L}^{-1}, 30 \mu \mathrm{g} \mathrm{L} \mathrm{L}^{-1}, 100 \mu \mathrm{g} \mathrm{L}^{-1}$, and $250 \mu \mathrm{g} \mathrm{L}^{-1}$ in toluene to ensure a well fitted calibration curve. For the curve fit function, a linear regression line going through point of origin was chosen, i.e. a function $(\mathrm{Y}=\alpha \mathrm{X})$ with $\mathrm{Y}$ as the area ratio between the compound and the internal standard, $\alpha$ as the slope and $\mathrm{X}$ as the concentration. All standard curves had correlation coefficients above 0.99 for the linear regression through the data points and therefore a satisfactory linear range. In Figure 2 the residual plot for the calibration curve of benzo[ $[a]$ pyrene is displayed. All residuals were between \pm 0.07 $\mu \mathrm{g} \mathrm{L}^{-1}$ and the studentized residuals were between \pm 2 .

[Insert Figure 2 here]

\section{Limit of detection and limit of quantification}

In order to determine the limit of detection (LOD) and limit of quantification (LOQ) 14 olive oil samples were spiked with $1 \mu \mathrm{g} \mathrm{kg}^{-1}$ of the compounds. The individual PAH level of each of the spiked olive samples was determined using the analytical method, and concentrations were calculated. LOD and LOQ were calculated using three and six times the standard deviation on the calculated amount in the spiked samples, respectively. The study of sensitivity indicated that the limit of detection ranged from 0.2 to $1.5 \mu \mathrm{g} \mathrm{kg}^{-1}$ oil for the individual compounds, and the estimated LOQs ranged from 0.3 to $3.0 \mu \mathrm{g} \mathrm{kg}^{-1}$ oil (Table 1 ).

The combination of GPC and further SPE clean-up resulted in relatively clean extracts, avoiding problems with chromatographic interferences for most compounds. Absolute 
recoveries were calculated for spiked olive oil samples relative to the internal standard (ISTD) added to the sample before clean-up. An example of the chromatogram for benzo[a]pyrene spiked at low level $\left(1 \mu \mathrm{g} \mathrm{kg}^{-1}\right)$ and the correlating internal standard benzo $[a]$ pyrene D12 are illustrated in Figure 3 left and right, respectively.

[Insert Figure 3 here]

The chromatogram revealed however, that benzo[b]fluoranthene and benzo[j]fluoranthene, being identified using the same mass (m/z: 252$)$, were only partly resolved. The peaks were split into two at the valley and quantified separately during the first part of the method development and method validation. However, it was recognised that it was not possible to quantify the two compounds individually, as high standards derivations were observed during validation mainly expected to be due to the problem of splitting the peaks.

Recovery, repeatability, intermediate reproducibility and measurement uncertainty In order to validate the analytical method, recovery results as well as the repeatability and intermediate reproducibility for olive oil spiked with the compounds were determined (Table 2). Three concentrations were used for spiking the oil during the method validation. For spiking level 1 approximately $1 \mu \mathrm{g} \mathrm{kg}^{-1}$ of PAHs standard was added to the olive oil, for spiking level 2: approximately $2 \mu \mathrm{g} \mathrm{kg}^{-1}$ was added and for spiking level 3: approximately $3 \mu \mathrm{g} \mathrm{kg}^{-1}$ was added. The repeatability includes analyses of a number of individual samples cleaned up and analysed in the same batch. The intermediate reproducibility includes clean-up and analysis of samples by different 
laboratory technicians, analysed in separate series using individual calibration curves and spiked samples made with two different olive oils.

The recovery of each compound was calculated after the concentration in the unspiked sample (olive oil) was subtracted from that found in the spiked sample and divided by the theoretical spiked concentration. Generally the average recoveries for all three spiking levels were 60 to 120 percent, except for acenaphthene $(59 \%$ for the recovery at $\left.1 \mu \mathrm{g} \mathrm{kg}^{-1}\right)$ and benzo[b]fluoranthene (142\% for the recovery at $2 \mu \mathrm{g} \mathrm{kg}^{-1}$ ) which were influenced by coeluting peaks, and phenanthrene (up to 178\%), fluoranthene (up to $188 \%$ ) and pyrene (up to $153 \%$ ) at the low spiking levels as the incurred level of the individual PAH in the unspiked sample was high compared to the spiking levels. Considerable uncertainty was therefore applied to these results. This fact can also be seen from the repeatability and intermediate reproducibility results. The HORRAT values were calculated (McClure and Lee, 2003): HORRAT= RSD [\%] / PRSD [\%] where PRSD is calculated using the Horwitz equation (Horwitz, 1982). The relative standard deviation for intermediate reproducibility lead to HORRAT values within the limits of acceptability $(0.02-1.3)$, except for benzo[b]fluoranthene at spiking level $2 \mu \mathrm{g}$ $\mathrm{kg}^{-1}$. The expanded measurement uncertainty was calculated using the lowest relative standard deviation for the intermediate reproducibility. The calculations resulted in a measurement uncertainty equivalent to the intermediate reproducibility, as the contributions from other factors were negligible. Results in Table 2 are therefore given as intermediate reproducibility as a measure for the measurement uncertainty. 
[Insert Table 2 here, landscape] 
The recovery for the internal standards has been calculated using the internal injection standard (benzo[e]pyrene $\mathrm{D}_{12}$ ) expressing the performance of the analytical method. The average recoveries of the internal standards for the three spiking levels are between 79 and 109 percent (Table 3).

[insert Tabel 3 about here]

In order to ensure quality during method validation, all analytical GC-MS series included analyses of a NIST CRM 1647d reference material, consisting of a standard solution in acetonitrile containing all the PAH compounds, except benzo[j]fluoranthene, benzo[ $e]$ pyrene and perylene. Furthermore, all series included the clean-up and analysis of at least one unspiked oil sample. The method has also been tested in a interlaboratory study provided by the UK Food Analysis Performance Assessment Scheme (FAPAS®) with excellent result e.g. Benzo[a]pyrene: FAPAS ${ }^{\circledR}$ assigned value $18.66 \mu \mathrm{g} / \mathrm{kg}$, result $18.5 \mu \mathrm{g} / \mathrm{kg}$, z-score 0.0 (FAPAS 2004).

\section{Benzo[a]pyrene levels in vegetable oils}

The average concentration of benzo[ $[a]$ pyrene (Table 4), the total sum of PAHs, the sum of genotoxic PAHs, and the sum of light and heavy PAHs (Table 5) were calculated using half of the LOD for results below LOD. Of the 69 vegetable oils analysed only one sample of sunflower oil at $11 \mu \mathrm{g} \mathrm{kg}^{-1}$ benzo[a]pyrene exceeded the EU maximum limit of $2 \mu \mathrm{g} \mathrm{kg}^{-1}$ (subtracted into a separate line in Table 4). Two of four grape seed oils 
had benzo[a]pyrene concentrations of 1.7 and $1.8 \mu \mathrm{g} \mathrm{kg}^{-1}$. All the other samples have contents below the EU maximum limit set in April 2005 (European Commission, 2005), and most samples have contents even below the LOD.

\section{[Insert Table 4 here]}

In the present study the data reported on rapeseed oils, the average concentration of benzo $[a]$ pyrene and the sum of PAHs (Table 5), correspond to the low levels previously reported for two deodorized rapeseed oils (Larsson et al., 1987) and rapeseed oils collected in three member states (European Commission, 2004). Refined rapeseed oils have been reported with benzo[a]pyrene concentrations well above $2 \mu \mathrm{g} \mathrm{kg}^{-1}$ and with increased levels of benzo[a]pyrene even for crude rapeseed oils $\left(1.4-64 \mu \mathrm{g} \mathrm{kg}^{-1}\right)$ (Dennis et al., 1991).

Levels of benzo $[a]$ pyrene in sunflower oils were found to range from $<0.2$ to $0.8 \mu \mathrm{g} \mathrm{kg}^{-}$ ${ }^{1}$, similar to the levels found by Speer and co-workers (1990).

In sesame oil, both the benzo[a]pyrene concentration $\left(0.2 \mu \mathrm{g} \mathrm{kg}^{-1}\right)$ and total sum of PAHs $\left(11 \mu \mathrm{g} \mathrm{kg}^{-1}\right)$ were similar to the levels found for rapeseed and sunflower oils. However, only one sample was analysed and more data is needed for this type of oil.

Total sum of PAHs in vegetable oils 
The total sum of PAHs for vegetable oils (Table 5) includes $17 \mathrm{PAHs}$ and was calculated by omitting phenanthrene, which was not detected in this survey. For sunflower oils $50 \%$ or more of the total concentration of PAHs analysed were carcinogenic (3.7 $\mu \mathrm{g} \mathrm{kg}^{-1}$ out of $7.4 \mu \mathrm{g} \mathrm{kg}^{-1}$ and $93 \mu \mathrm{g} \mathrm{kg}^{-1}$ out of $172 \mu \mathrm{g} \mathrm{kg}^{-1}$ ), while for the vegetable oils in general less than $25 \%$ of the total sum of PAHs were found to belong to the genotoxic compounds.

[Insert Table 5 here]

Three grape seed oils, three virgin olive oils and one single sunflower oil had a total sum of PAHs above the suggested limit of $25 \mu \mathrm{g} \mathrm{kg}$-1 for the total sum of PAHs (Speer et al., 1990; Swetman et al., 1999). While more and more PAHs are included in the analysis, the limit of $25 \mu \mathrm{g} \mathrm{kg}^{-1}$ for the total sum of PAHs has been remarked as unrealistic, especially if dealing with unrefined products such as extra virgin olive oil containing up to $110 \mu \mathrm{g} \mathrm{kg}^{-1}$ PAHs (Speer et al., 1990; Moret et al., 1997). For data obtained in this study it is important to notice that when omitting phenanthrene, the PAH compound most abundant in e.g. grape seed oil, lower total sums of PAHs are obtained which might explain the lower results.

The average sum of PAHs in the virgin olive oil samples was in agreement with previous studies (Menichini et al., 1991; Moret et al., 1997; Moret and Conte, 2000) found to be higher than the average sum of PAHs for the olive oils (a blend of refined and virgin oils) (Table 5). These results has previously been explained by the olive oil 
blend being exposed to a PAHs reduction in the oil refining processes (Larsson et al., 1987).

Two grape seed oils and two sunflower oils had a sum of heavy PAHs (5 or more aromatic rings) exceeding $5 \mu \mathrm{g} \mathrm{kg}^{-1}$. Using the limit of the sum of heavy PAHs corresponds well to the fact that 12 of 15 genotoxic compounds assessed by SCF (European Commission, 2002) contain five or more aromatic rings.

Comparing the level of light PAHs for all oil samples, only sunflower (app. 50\%) and rapeseed oils (70\%) have levels of light PAHs less than $90 \%$ of the total sum of PAHs, indicating the use of a refining process. For vegetable oils the refining process includes a bleaching step, a treatment with activated carbon removing a considerable amount of PAHs, while the deodorizing step removes some of the light PAHs and has little effect on the heavy PAHs. Therefore a total reduction in the amount of light PAHs indicates the inclusion of a refining step in the vegetable oil production.

\section{Conclusions}

The presented analytical method makes it possible to meet the performance criteria for the limit of detection (LOD) and the recovery, as described in the EC document laying down methods of analysis for the official control of the levels of benzo[ $a]$ pyrene in foods. The criteria for LOD is set to no more than $0.3 \mu \mathrm{g} \mathrm{kg}^{-1}$ and the recovery between $50 \%$ and $120 \%$. 


\section{Acknowledgements}

We wish to thank Vera Klausen and Vibeke Balswel from the Danish Institute for Food and Veterinary Research, as well as Anni Mårbjerg Thomsen and Thomas Dyekjær from the Regional Veterinary and Food Administration Center, Region North for their skilful technical assistance with the chemical analyses.

\section{References}

Bolt D. B, Bradley, J.C. and Re, M.A. 1997 The preparation of ${ }^{13} \mathrm{C}$-labled standards of polycyclic aromatic hydrocarbons and other micropollutants: Synthetic and QA/QC considerations. Chemosphere 34 5-7: 905-913. 
Danak 2003. RL 1 Validation of methods in chemical analytical laboratories quantitative methods of analysis (in Danish: RL 1 Metodevalidering i kemisk analytiske laboratorier). Available: http://www2.danak.dk/akkreditering/RL/RL1.pdf via the INTERNET. Accessed 2006 Nov 10.

Dennis, M., J., Massey, R.,C., Cripps, G., Venn, I., Howarth, N., and Lee, G. 1991. Factors affecting the polycyclic aromatic hydrocarbon content of cereals, fats and other food products. Food Additives and Contaminants. 8: 517-530.

European Commission, 2002. Opinion of the Scientific Committee on Food on the risks to human health of Polycyclic Aromatic Hydrocarbons in food.

SCF/CS/CNTM/PAH/29/Final.

European Commission, 2004. Report on experts participating in Task 3.2.12.

Collection of occurrence data on polycyclic aromatic hydrocarbons in food.

European Commission , 2005. Commission Regulation (EC) No 208/2005 of 4

February 2005 amending Regulation (EC) No 466/2001 as regards polycyclic aromatic hydrocarbons. Official Journal of the European Union, L 34/3.

European Commission , 2005a. Commission Directive 2005/10/EC of 4 February 2005 laying down sampling methods and the methods of analysis for the official control of the levels of benzo $(a)$ pyrene in foodstuffs. Official Journal of the European Union, L $34 / 15$. 
European Commission , 2005b. Commission Recommendation of 4 February 2005 on further investigation into the levels of polycyclic aromatic hydrocarbons in certain foods. Official Journal of the European Union, L 34/43.

Fapas 2004. Enviromental contaminants FAPAS ${ }^{\circledR}$ Series 6 Round 18, May - July 2004, Report No. 0618.

McClure, F.D. and Lee, J.K. 2003. Computation of HORRAT values. Journal of AOAC international. 86: 1056-1058.

Horwitz, W. 1982. Evaluation of analytical methods used for regulation of foods and drugs. Analytical Chemistry. 54: 67A-76A.

Hopia, A., Pyysalo, H., and Wickström, K. 1986. Margarines, butter and vegetable oils as sources of poilycyclic aromatic hydrocarbons. Journal of the American Oil Chemists' Society. 63: 889-893.

IPCS, 1998. Selected non-heterocyclic Polycyclic Aromatic Hydrocarbons.

Environmental Health Criteria No. 202. International Programme on Chemical Safety, World Health Organisation. Geneva 1998.

ISO 1993. BIPM, IEC, IFCC, ISO, IUPAC, IUPAP, OIML: Guide to the expression of uncertainty in measurement. Geneva 1993. 
ISO 2005. General requirements for the competence of testing and calibration laboratories (ISO/IEC 17025:2005). Geneva 2005.

Larsson, B.K., Eriksson, A.T., and Cervenka, M. 1987. Polycyclic aromatic hydrocarbons in crude and deodorized vegetable oils. Journal of American Oil Chemist's Society. 64: 365-370.

Lodovici, M., Dolara, P., Casalini, C., Ciappellano, S., and Testolin, G. 1995.

Polycyclic aromatic hydrocarbon contamination in the Italian diet. Food Additives and Contaminants. 12: 703-713.

Menichini, E., Bocca, A., Merli, F., Ianni, D., and Monfredini, F. 1991. Polycyclic aromatic hydrocarbons in olive oils on the Italian market. Food Additives and Contaminants. 8: 363-369.

Moret, S. and Conte, L.S. 2000. Polycyclic aromatic hydrocarbons in edible fats and oils: Occurrence and analytical methods. Review. Journal of Chromatography A. 882: 245-253.

Moret, S., Dudine, A., and Conte, L.S. 2000. Processing effects on the polyaromatic hydrocarbon content of grapeseed oil. Journal of the American Oil Chemists' Society. 77: 1289-1292. 
Moret, S., Piani, B., Bortolomeazzi, R., and Conte, L.S. 1997. HPLC determination of polycyclic aromatic hydrocarbons in olive oils. Zeitschrift für LebensmittelUntersuchung und -Forschung A. 205:116-120.

Pupin, A.M. and Toledo, M.C.F. 1996. Benzo(a)pyrene in olive oils on the Brazilian market. Food Chemistry. 55: 185-188.

Speer, K., Steeg, E., Horstmann, P., Kühn, Th., and Montag, A. 1990. Determination and distribution of polycyclic aromatic hydrocarbons in native vegetable oils, smoked fish products, mussels and oysters, and bream from the river Elbe. Journal of High Resolution Chromatography 13:104-111.

Swetman, T., Head, S., and Evans, D. 1999. Contamination of coconut oil by PAH. Inform - International News on Fats Oils and Related Materials 10: 706-712.

Van der Wielen, J.C.A., Jansen, J.T.A., Martena, M.J., De Groot, H.N., In’t Veld, P.H. 2006. Determination of the level of benzo[a]pyrene in fatty foods and food supplements. Food Additives and Contaminants 23: 709-714. 
Table 1. Compounds included in the method and method performance. LOD and LOQ expressed as $\mu_{\mathrm{g} \mathrm{kg}} \mathrm{koil}^{-1}$

\begin{tabular}{lccccc}
\hline Compound & Formula & MW & RT & LOD & LOQ \\
\hline Acenaphthylene & $\mathrm{C}_{12} \mathrm{H}_{8}$ & 152.2 & 15.0 & 0.4 & 0.7 \\
Acenaphthylene ${ }^{\mathbf{1 3}} \mathbf{C}_{\mathbf{6}}$ & $\mathrm{C}_{12} \mathrm{H}_{8}$ & 158.2 & $\mathbf{1 5 . 0}$ & - & - \\
Acenaphthene & $\mathrm{C}_{12} \mathrm{H}_{10}$ & 154.2 & 15.6 & 1.5 & 3.0 \\
\hline Fluorene & $\mathrm{C}_{13} \mathrm{H}_{10}$ & 166.2 & 17.4 & 0.6 & 1.2 \\
Fluorene ${ }^{\mathbf{1 3}} \mathbf{C}_{\mathbf{6}}$ & $\mathrm{C}_{13} \mathrm{H}_{10}$ & 172.2 & $\mathbf{1 7 . 4}$ & - & - \\
Phenanthrene & $\mathrm{C}_{14} \mathrm{H}_{10}$ & 178.2 & 20.7 & 1.3 & 2.6 \\
Anthracene & $\mathrm{C}_{14} \mathrm{H}_{10}$ & 178.2 & 20.8 & 0.2 & 0.5 \\
\hline Fluoranthene & $\mathrm{C}_{16} \mathrm{H}_{10}$ & 202.3 & 24.7 & 1.2 & 2.3 \\
Pyrene & $\mathrm{C}_{16} \mathrm{H}_{10}$ & 202.3 & 25.5 & 1.2 & 2.3 \\
Benzo[a]anthracene $\mathbf{D}_{\mathbf{1 2}}$ & $\mathrm{C}_{18} \mathrm{D}_{12}$ & 240.3 & $\mathbf{3 0 . 0}$ & - & - \\
Benzo[a]anthracene & $\mathrm{C}_{18} \mathrm{H}_{12}$ & 228.3 & 30.0 & 0.4 & 0.9 \\
Chrysene & $\mathrm{C}_{18} \mathrm{H}_{12}$ & 228.3 & 30.2 & 0.3 & 0.6 \\
\hline Benzo[b]fluoranthene & $\mathrm{C}_{20} \mathrm{H}_{12}$ & 252.3 & 36.0 & 0.6 & 1.2 \\
Benzo[j]fluoranthene & $\mathrm{C}_{20} \mathrm{H}_{12}$ & 252.3 & 36.1 & 0.5 & 1.0 \\
Benzo[k]fluoranthene & $\mathrm{C}_{20} \mathrm{H}_{12}$ & 252.3 & 36.3 & 0.5 & 1.1 \\
Benzo[e]pyrene $\boldsymbol{D}_{\mathbf{1 2}}$ & $\mathrm{C}_{20} \mathrm{D}_{12}$ & 264.2 & 37.6 & - & - \\
Benzo[e]pyrene & $\mathrm{C}_{20} \mathrm{H}_{12}$ & 252.3 & 37.8 & 0.3 & 0.5 \\
Benzo[a]pyrene $\mathbf{D}_{\mathbf{1 2}}$ & $\mathrm{C}_{20} \mathrm{D}_{12}$ & 264.2 & $\mathbf{3 8 . 0}$ & - & - \\
Benzo[a]pyrene & $\mathrm{C}_{20} \mathrm{H}_{12}$ & 252.3 & 38.2 & 0.2 & 0.5 \\
Perylene & $\mathrm{C}_{20} \mathrm{H}_{12}$ & 252.3 & 38.7 & 0.3 & 0.5 \\
\hline Indeno[ $[, 2,3-c, d] p y r e n e$ & $\mathrm{C}_{20} \mathrm{H}_{12}$ & 276.3 & 44.0 & 0.3 & 0.6 \\
Indeno[1,2,3-c,d]pyrene $\mathbf{D}_{\mathbf{1 2}}$ & $\mathrm{C}_{22} \mathrm{D}_{12}$ & 288.4 & $\mathbf{4 3 . 9}$ & - & - \\
Dibenzo[a,h]anthracene & $\mathrm{C}_{22} \mathrm{H}_{14}$ & 278.4 & 44.2 & 0.9 & 1.8 \\
Benzo[g,h,i]perylene & $\mathrm{C}_{22} \mathrm{H}_{12}$ & 276.3 & 45.2 & 0.2 & 0.3 \\
\hline
\end{tabular}


Table 2. Recovery, repeatability relative standard deviation $\left(R S D_{r}\right)$, intermediate reproducibility relative standard deviation $\left(R S D_{R}\right)$ and Horrat values for the spiking level $1 \mu \mathrm{g} \mathrm{kg}^{-1}, 2 \mu \mathrm{g} \mathrm{kg}$ and $3 \mu \mathrm{g} \mathrm{kg}$.

\begin{tabular}{|c|c|c|c|c|c|c|c|c|c|c|c|c|}
\hline & \multicolumn{3}{|c|}{ Recovery [\%] } & \multicolumn{3}{|c|}{ RSD $_{\mathbf{r}}[\%]$} & \multicolumn{3}{|c|}{$\mathbf{R S D}_{\mathbf{R}}[\%]$} & \multicolumn{3}{|c|}{ Horrat value } \\
\hline & $1 \mu \mathrm{g} \mathrm{kg}^{-1}$ & $2 \mu \mathrm{g} \mathrm{kg}^{-1}$ & $3 \mu \mathrm{g} \mathrm{kg}^{-1}$ & $1 \mu \mathrm{g} \mathrm{kg}^{-1}$ & $2 \mu \mathrm{g} \mathrm{kg}^{-1}$ & $3 \mu \mathrm{g} \mathrm{kg}^{-1}$ & $1 \mu \mathrm{g} \mathrm{kg}^{-1}$ & $2 \mu \mathrm{g} \mathrm{kg}^{-1}$ & $3^{\text {a) }} \mu \mathrm{g} \mathrm{kg}^{-1}$ & $1 \mu \mathrm{g} \mathrm{kg}^{-1}$ & $2 \mu \mathrm{g} \mathrm{kg}^{-1}$ & $3 \mu \mathrm{g} \mathrm{kg}^{-1}$ \\
\hline $\mathrm{N}$ & 14 & 13 & 9 & 3 & 5 & 5 & 5 & 5 & 2 & 5 & 5 & 2 \\
\hline Acenaphtylene & 78 & 76 & 75 & 1 & 2 & 1 & 6 & 8 & 6 & 0.1 & 0.2 & 0.2 \\
\hline Acenaphthene & 59 & 68 & 85 & 24 & 26 & 12 & 22 & 50 & 26 & 0.5 & 1.3 & 0.7 \\
\hline Fluorene & 72 & 77 & 79 & 21 & 12 & 5 & 15 & 13 & 1 & 0.3 & 0.3 & 0.0 \\
\hline Phenanthrene & 84 & 99 & 82 & 7 & 5 & 3 & 1 & 28 & 4 & 0.02 & 0.7 & 0.1 \\
\hline Anthracene & 94 & 89 & 90 & 5 & 8 & 5 & 11 & 12 & 1 & 0.2 & 0.3 & 0.0 \\
\hline Fluoranthene & 111 & 113 & 97 & 12 & 8 & 8 & 7 & 16 & 10 & 0.2 & 0.4 & 0.3 \\
\hline Pyrene & 86 & 119 & 93 & 13 & 12 & 7 & 6 & 24 & 10 & 0.1 & 0.6 & 0.3 \\
\hline Benzo $[a]$ anthracene & 89 & 87 & 80 & 7 & 8 & 6 & 8 & 17 & 4 & 0.2 & 0.4 & 0.1 \\
\hline Chrysene & 90 & 80 & 82 & 3 & 6 & 4 & 3 & 11 & 1 & 0.1 & 0.3 & 0.0 \\
\hline Benzo[j]fluoranthene & 88 & 95 & 88 & 12 & 17 & 8 & 15 & 16 & 30 & 0.3 & 0.4 & 0.8 \\
\hline Benzo $[b]$ fluoranthene & 100 & 142 & 135 & 20 & 79 & 30 & 9 & 86 & 8 & 0.2 & 2.2 & 0.2 \\
\hline Benzo $[k]$ fluoranthene & 70 & 73 & 70 & 13 & 8 & 11 & 11 & 11 & 3 & 0.2 & 0.3 & 0.1 \\
\hline Benzo[e]pyrene & 89 & 85 & 92 & 5 & 4 & 6 & 3 & 9 & 7 & 0.1 & 0.2 & 0.2 \\
\hline Benzo $[a]$ pyrene & 87 & 85 & 89 & 1 & 3 & 4 & 8 & 7 & 1 & 0.2 & 0.2 & 0.0 \\
\hline Perylene & 86 & 82 & 88 & 4 & 5 & 4 & 4 & 7 & 2 & 0.1 & 0.2 & 0.1 \\
\hline Indeno[ $[1,2,3-c, d]$ pyrene & 81 & 80 & 81 & 7 & 9 & 5 & 8 & 15 & 12 & 0.2 & 0.4 & 0.3 \\
\hline Dibenzo $[a, h]$ anthracene & 120 & 102 & 94 & 19 & 13 & 6 & 15 & 18 & 7 & 0.3 & 0.5 & 0.2 \\
\hline Benzo $[g, h, i]$ perylene & 65 & 60 & 68 & 10 & 14 & 5 & 18 & 29 & 15 & 0.4 & 0.7 & 0.4 \\
\hline
\end{tabular}


Table 3. Recovery of labelled compounds for the spiking level $1 \mu \mathrm{g} \mathrm{kg}^{-1}, 2 \mu \mathrm{g} \mathrm{kg}^{-1}$ and 3 $\mu \mathrm{kg}^{-1}$ [percent].

\begin{tabular}{|c|c|c|c|}
\hline & \multicolumn{3}{|c|}{ Recovery [\%] } \\
\hline & $1 \mu \mathrm{g} \mathrm{kg}^{-1}$ & $2 \mu \mathrm{g} \mathrm{kg}^{-1}$ & $3 \mu \mathrm{g} \mathrm{kg}^{-1}$ \\
\hline $\mathrm{N}$ & 14 & 13 & 9 \\
\hline Acenaphthylene ${ }^{13} \mathrm{C}_{6}$ & 89 & 101 & 104 \\
\hline Fluorene ${ }^{13} \mathrm{C}_{6}$ & 93 & 106 & 109 \\
\hline Benzo $[a]$ anthracene $\mathrm{D}_{12}$ & 93 & 82 & 95 \\
\hline Benzo $[a]$ pyrene $\mathrm{D}_{12}$ & 94 & 79 & 91 \\
\hline Indeno $[1,2,3-c, d]$ pyrene $\mathrm{D}_{12}$ & 97 & 80 & 93 \\
\hline
\end{tabular}


Table 4. Average, ranges and median of benzo[a]pyrene concentration in $\mu \mathrm{g} \mathrm{kg^{-1 }}$ for vegetable oils analysed with country of origin including values for references.

\begin{tabular}{lccccl}
\hline Vegetable oil & N & Average & Range & Median & \multicolumn{1}{c}{ Origin } \\
\hline Olive oil, extra virgin & 46 & 0.15 & $<0.2-0.4$ & 0.10 & IT, ES, GR, FR, NL \\
Olive oil & 6 & 0.12 & $<0.2-0.2$ & 0.10 & IT, ES \\
Rapeseed oil & 8 & 0.15 & $<0.2-0.3$ & 0.10 & DK, BE, DE, AT \\
Sunflower oil & 3 & 0.4 & $<0.2-0.8$ & 0.3 & IT \\
Sunflower oil & 1 & 11 & & & NL \\
Grape seed oil & 4 & 1.0 & $0.2-1.8$ & 1.0 & IT, ES, BE \\
Sesame oil & 1 & 0.2 & & & DE
\end{tabular}

\begin{tabular}{|c|c|c|c|c|c|}
\hline & & & & & \\
\hline Virgin olive oil & 671 & 0.4 & $0.015-32$ & 0.2 & European Comm., 2004 \\
\hline Virgin olive oil & 2 & & $<0.02-0.7$ & & Hopia et al., 1986 \\
\hline Virgin olive oil & 52 & & $<0.015-1.2$ & & Moret et al., 1997 \\
\hline Virgin olive oil & 6 & & $<3$ & & Menichini et al., 1991 \\
\hline Virgin olive oil & 3 & 0.1 & & & Lodovici et al., 1995 \\
\hline Olive oil & 280 & 1.7 & $0.03-89$ & 0.3 & European Comm., 2004 \\
\hline Olive oil & 32 & & $0.5-164$ & & Pupin and Toledo, 1996 \\
\hline Olive pomace oil & 268 & 18 & $<0.1-206$ & 9.6 & European Comm., 2004 \\
\hline Olive oil & 7 & 0.7 & $0.2-1.2$ & & Speer et al., 1990 \\
\hline Rapeseed oil, deod. & 2 & 0.8 & $0.3-1.3$ & & Larsson et al., 1987 \\
\hline Rapeseed oil & 18 & 0.3 & $<0.03-1.3$ & 0.1 & European Comm., 2004 \\
\hline Refined rapeseed oil & 24 & 1.8 & $0.3-69$ & & Dennis et al., 1991 \\
\hline Sunflower oil & 5 & 0.7 & $<0.1-0.8$ & & Speer et al., 1990 \\
\hline Sunflow & 201 & 3.1 & $<0.015-232$ & 0.4 & European Comm., 2004 \\
\hline Grape sc & 92 & 4.2 & $0.05-73$ & 0.6 & European Comm., 2004 \\
\hline Grape seed oil & 20 & 20 & $8.6-44$ & & Moret et al., 2000 \\
\hline
\end{tabular}

Deod. = deodorized oil.

Origin codes: $\mathrm{AT}=$ Austria, $\mathrm{BE}=$ Belgium, $\mathrm{DE}=$ Germany, $\mathrm{DK}=$ Denmark, $\mathrm{ES}=$ Spain, $\mathrm{FR}=$ France, $\mathrm{GR}=$ Greece, IT = Italy, NL = Holland. 
Table 5. Average and ranges of total sum of PAHs, sum of genotoxic PAHs and sums of light and heavy PAHs in $\mu \mathrm{g} \mathrm{kg}^{-1}$ for vegetable oils analysed.

\begin{tabular}{lccccc}
\hline \multicolumn{1}{c}{ Vegetable oil } & $\mathrm{N}$ & $\begin{array}{c}\text { Total PAHs } \\
\text { Average }\end{array}$ & $\begin{array}{c}\text { Genotoxic PAHs }^{\mathrm{a})} \\
\text { Average }\end{array}$ & $\begin{array}{c}\text { Light PAHs }^{\mathrm{b})} \\
\text { Average }\end{array}$ & $\begin{array}{c}\text { Heavy PAHs }^{\mathrm{c})} \\
\text { Average }\end{array}$ \\
\hline Olive oil, extra & & & & & \\
virgin & 46 & 16 & 2.7 & 15 & 1.6 \\
Olive oil & 6 & 8.1 & 1.9 & 6.8 & 1.3 \\
Rapeseed oil & 8 & 5.5 & 1.3 & 4.0 & 1.5 \\
Sunflower oil & 3 & 7.4 & 3.7 & 3.8 & 3.7 \\
Sunflower oil & 1 & 172 & 93 & 97 & 75 \\
Grape seed oil & 4 & 42 & 11 & 35 & 7.2 \\
Sesame oil & 1 & 11 & 1.6 & 9.8 & 1.2 \\
\hline
\end{tabular}

${ }^{a)}$ Genotoxic PAHs include the sum of benzo[a]anthracene, chrysene, benzo[ $\left.b+j\right]$ fluoranthene, benzo $[k]-$ fluoranthene, benzo[ $a]$ pyrene, indeno[ $[1,2,3-c, d]$ pyrene, dibenzo[a,h]anthracene, and benzo[g,h,i]perylene.

${ }^{b}$ Light PAHs (4 or less aromatic rings) include the sum of acenaphthylene, acenaphthene, fluorene, anthracene, fluoranthene, pyrene, benzo $[a]$ anthracene and chrysene

${ }^{c}$ Heavy PAHs (5 or more aromatic rings) include the sum of benzo[ $\left.b+j\right]$ fluoranthene, benzo[ $\left.k\right]$ fluoranthene, benzo $[e]$ pyrene, benzo $[a]$ pyrene, perylene, indeno $[1,2,3-c, d]$ pyrene, dibenzo[a,h]anthracene, benzo[g,h,i]perylene. 


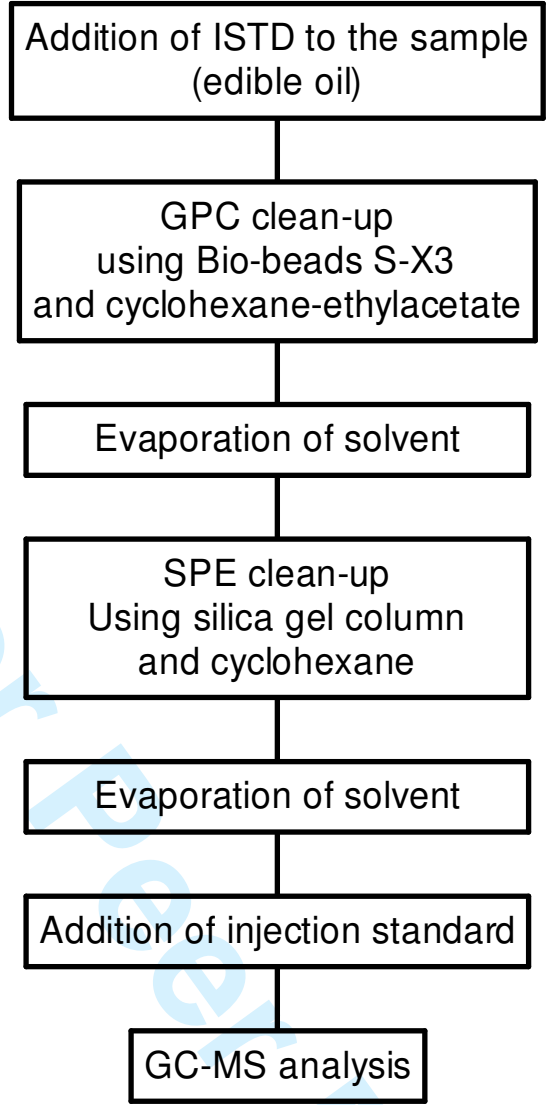

Figure 1. Procedure for sample preparation of edible oils. 


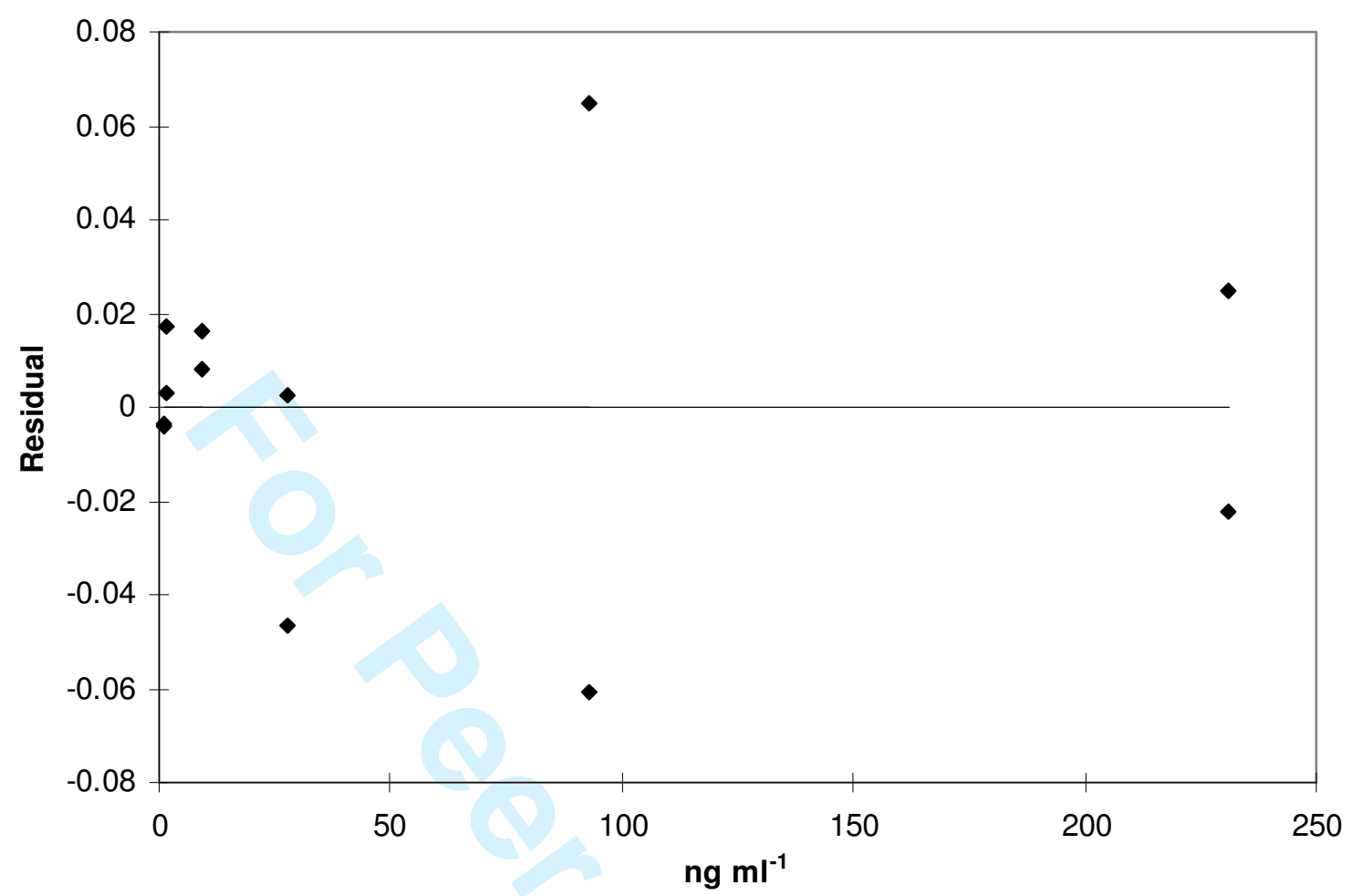

Figure 2. Residual plot for the calibration curve of benzo[a]pyrene showing two standards analyzed at each concentration level. 

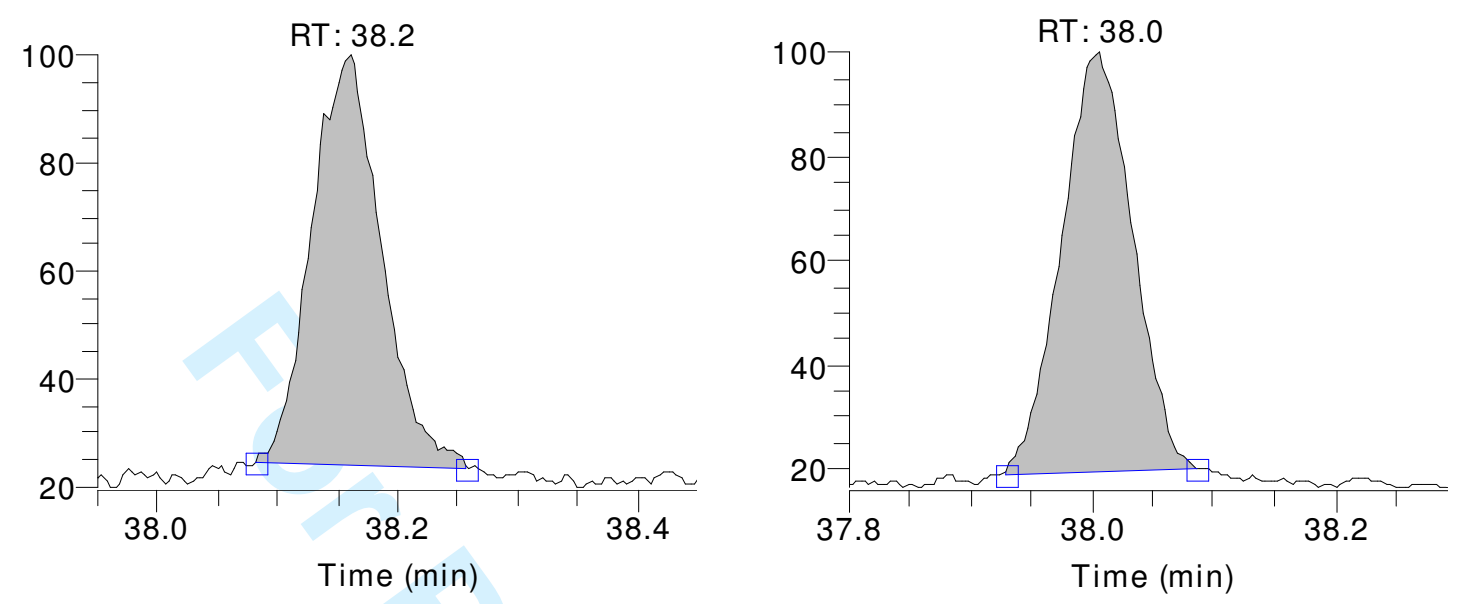

Figure 3. The chromatogram for benzo[a]pyrene in olive oil added $1 \mu \mathrm{g} \mathrm{kg}{ }^{-1} \mathrm{PAH}$ standard (left) and the corresponding internal standard benzo[a]pyrene D12 (right). 